\title{
IRON INCRUSTATION OF THE PULMONARY VESSELS IN PATENT DUCTUS ARTERIOSUS WITH CONGENITAL MITRAL DISEASE
}

\author{
BY \\ KENNETH W. WALTON AND DONALD HEATH \\ From the Departments of Experimental Pathology and Pathology, University of Birmingham
}

The clinical and pathological features of patent ductus arteriosus with pulmonary hypertension are presented in the following case report. The structural changes in the lung provide an example of the rare finding of iron incrustation of the elastic laminæ of the pulmonary vessels in association with congenital heart disease. This case demonstrates the importance of pre-operative lung biopsy in patients selected for cardiac surgery, especially when detailed cardiac catheterization is not performed. Had a biopsy of this type been taken at an earlier stage in this instance, a further unsuspected congenital anomaly, associated with the ductus, would have been detected.

\section{Clinical Features}

The patient, an only child, weighed $6 \mathrm{lb}$. at birth in 1950 . His mother's health had been normal during the pregnancy and, in particular, there was no history of rubella. He had frequent coughs and colds during infancy and for this reason was referred for examination at the age of 9 months, when it was found that there was a loud, short systolic murmur, which was maximal in the third left inter-space and was conducted over the whole præcordium. At that time there was no cardiomegaly and the child was acyanotic, but, by June 1953, cyanosis was obvious. By the following year the exercise tolerance was poor and attacks of bronchitis were frequent so that he was admitted for diagnosis and to study the possibility of corrective surgery.

On examination he was found to be a well-grown boy weighing $30 \mathrm{lb}$. who looked flushed and had slight cyanosis of the lips at rest. Finger clubbing was absent. There was considerable enlargement of the heart, the tapping apex beat being felt in the sixth left intercostal space in the anterior axillary line. On auscultation there was a loud, split first sound at the apex and an accentuated, split second sound at the base. A loud systolic murmur was heard all over the præcordium; this was maximal to the left of the sternum in the fourth left interspace and was heard faintly over the back. At the apex there were systolic and mid-diastolic murmurs with accompanying thrills. The liver was enlarged two finger breadths below the right costal margin. Occasional râles were heard over both lungs. The blood pressure was 110/60.

An electrocardiogram demonstrated sinus rhythm at the rate of 130 a minute with a $P-R$ interval of 0.16 seconds. There was right axis deviation of an electrically vertical heart and evidence of right ventricular preponderance. A fluoroscopic examination showed the heart to be enlarged, and there was a prominent pulmonary segment, an enlarged left atrium, and pulmonary congestion: the aorta was small. The hæmoglobin level was 116 per cent. Cardiac catheterization showed the pulmonary artery mean blood pressure to be $100 \mathrm{~mm}$. $\mathrm{Hg}$ with no evidence of abnormally increased oxygen saturation of blood in the right chambers of the heart.

The child was admitted again in May, 1957. The clinical signs of pulmonary arterial hypertension were more apparent but otherwise the results of clinical examination were as found three years earlier. Cyanosis was still slight. It seemed most likely that he had a patent ductus arteriosus with nearly balanced pulmonary and systemic blood pressure and he was referred to Mr. d'Abreu for ligation of the ductus. A preoperative radiograph showed enlargement of the right ventricle and the left atrium, and congested lungs. 
At operation, the central cyanosis became more apparent under anæsthesia. The suspected widely patent ductus was found and the lungs were very hyperæmic and œdematous. The heart was irritable and periods of arrhythmia necessitated several halts during the operation. The ductus was clamped for 10 minutes with no apparent ill effect on the right ventricle, so division was performed and a lung biopsy taken. The child developed peripheral circulatory failure following the operation and died.

Lung Biopsy Report (Dr. A. H. Cameron). The changes in the lung were unexpected in so far as they were atypical of patent ductus with pulmonary arterial hypertension and more suggestive of severe pulmonary venous hypertension.

There were marked vascular changes and also some alteration of the parenchyma. The arteries and arterioles were thick-walled due to muscular hypertrophy and intimal cellular fibrosis. The elastic tissue of the blood vessels, including the small veins, was encrusted with iron and calcium and there was occasionally a foreign body giant-cell reaction. The alveoli were large and emphysematous and many showed cuboidal metaplasia of the lining cells. There were several foci of collapsed alveoli filled with hæmosiderin-laden phagocytes. The interstitial tissue between the alveoli was increased in places and the elastic fibres in this situation were also encrusted with mineral.

\section{Autopsy Report}

The heart was found to be enlarged, weighing $250 \mathrm{~g}$. The expected dilatation and hypertrophy of the right atrium and ventricle were present but in addition there was dilatation and hypertrophy of the left cardiac chambers. There was endocardial fibro-elastosis in the left atrium and left ventricle; it was prominent in the atrium but much less severe in the ventricle. The mitral valve was thickened and fibrous with partial fusion of the commissures; it was incompetent, the orifice of the valve admitting the tips of three fingers. The line of apposition of the cusps showed a rugose thickening of the endocardium but there was no evidence of active rheumatic vegetations. The chordæ tendineæ were thickened, fibrotic, and shortened and there was fibrosis of the papillary muscles (Fig. 1). The aortic, pulmonary, and tricuspid valves were normal. The aorta was narrow and hypoplastic. The main pulmonary trunk and its primary subdivisions showed many subintimal atheromatous deposits. The left lung was partially collapsed. Both lungs on

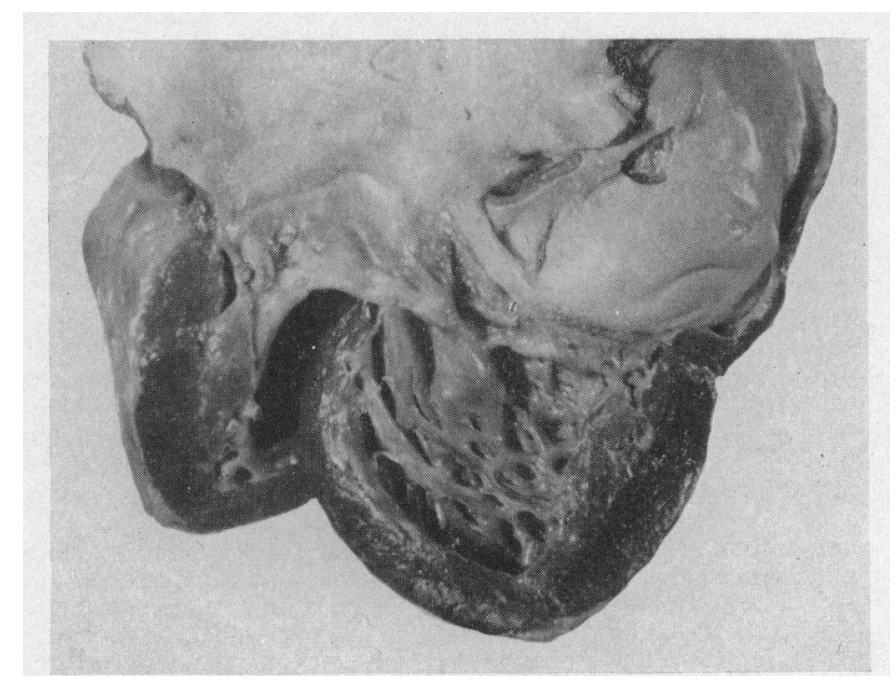

FIG. 1.-The heart opened through the left ventricle to show the abnormal mitral valve. Both valve cusps and chordæ tendineæ are severely fibrosed and thickened. The chordæ are contracted. There is fibrosis of the papillary muscles. Endocardial fibro-elastosis is seen in the left atrium. 
section showed prominence of the pulmonary arteries which projected conspicuously from the cut surfaces. There were many small brown areas seen in the lung parenchyma and the hilar, tracheo-bronchial, and mediastinal lymph nodes were enlarged and brown in colour. There were suture lines in the aorta and pulmonary artery corresponding in position with the sites of excision of the ductus arteriosus. There was an old infarct of the left kidney. The diagnosis was a patent ductus that had been divided and organic mitral valvular regurgitation.

Histology of the Pulmonary Vessels. The elastic pulmonary arteries (>1000 $\mu$ in diameter) were atheromatous. The elastic fibrils of the media of these large vessels were long, uniform, and without branches: they ran parallel with one another as in the aorta (Fig. 2a). In this way the configuration of the elastica of the media resembled that of the fotal pulmonary trunk rather than that of the normal adult

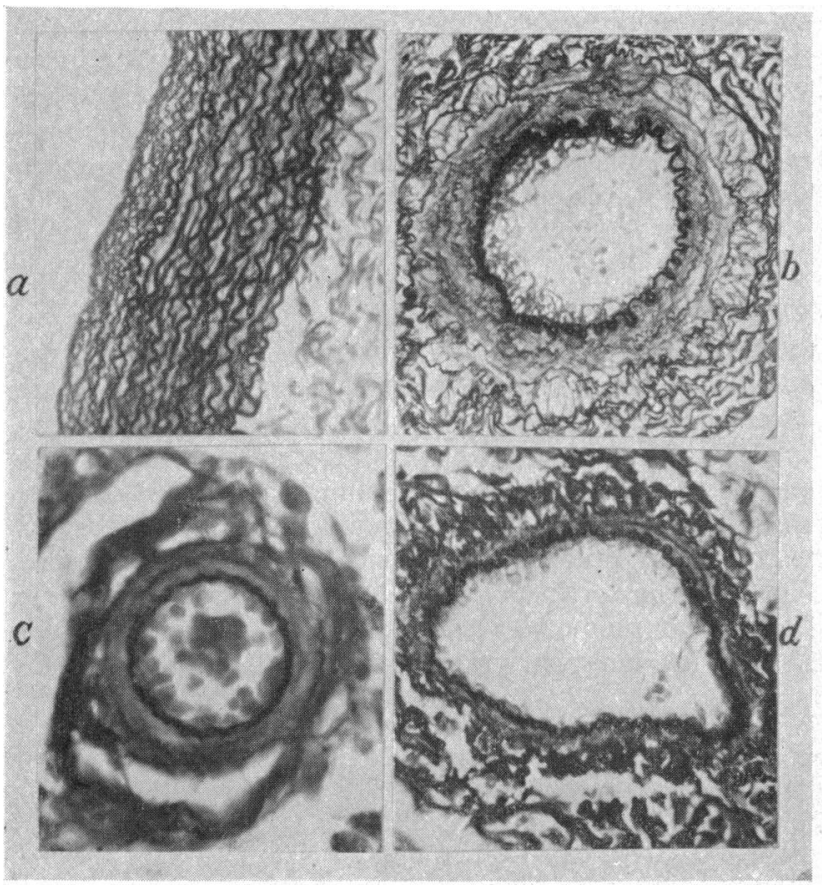

FIG. 2

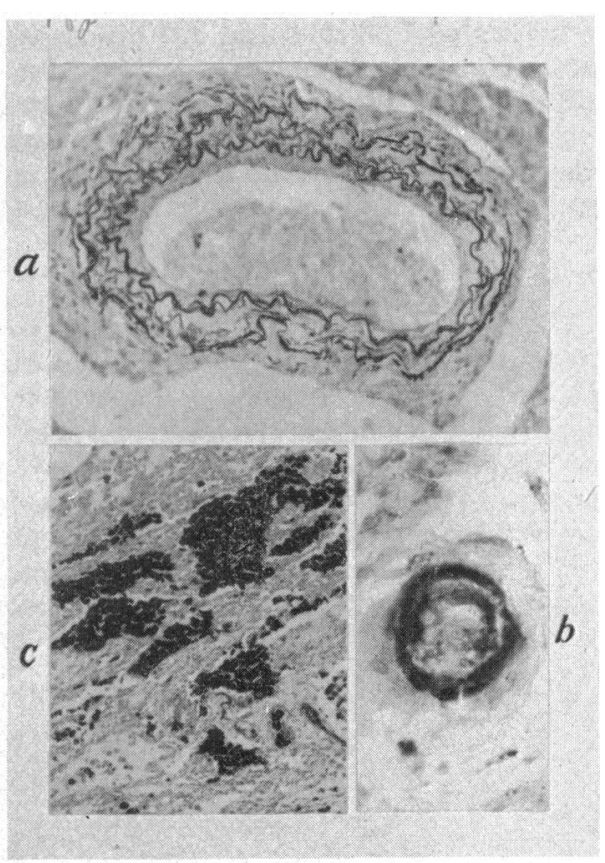

FIG. 3

Fig. 2.-All sections were stained by the Lawson modification of the Weigert-Sheridan method to demonstrate elastic and were counterstained with Van Gieson's stain to show muscle and collagen.

Upper left (a) Part of transverse section of an elastic pulmonary artery showing long, uniform, non-branching elastic fibrils. This configuration of elastic tissue, resembling that of the aorta or foetal pulmonary trunk, is found in the adult pulmonary trunk when it has been subjected to severe pulmonary arterial hypertension from birth (X 110).

Upper right (b) Transverse section of a muscular pulmonary artery showing medial hypertrophy. Note the development of fasciculi of longitudinal muscle fibres in the external part of the media. There is slight cellular intimal proliferation with splitting of the thick internal elastic lamina. The adventitia is thick and fibrous $(\times 110)$.

Lower left (c) Transverse section of a pulmonary arteriole. The vessel is abnormal in having a thick muscular media. The wall of a normal pulmonary arteriole consists of a single elastic lamina $(\times 280)$.

Lower right (d) Transverse section of a pulmonary vein, which is abnormal in having a thick muscular media sandwiched between two distinct elastic laminæ. The media has hypertrophied as a response to the pulmonary venous hypertension to such an extent that it resembles a muscular pulmonary artery in structure $(x 170)$.

FIG. 3.-All sections were stained with Perls' reagents to demonstrate ferric iron.

Above (a) Transverse section of a muscular pulmonary artery showing the iron incrustation of the elastic laminæ $(\times 110)$.

Lower right (b) Transverse section of a pulmonary arteriole showing the iron incrustation of the elastic laminæ $(\times 420)$.

Lower left (c) Section of lung showing a focus of hæmosiderin-containing macrophages $(\times 75)$. 
pulmonary trunk which is characterized by a loosely arranged network of fragmented, branched fibrils, often with club-like terminal expansions.

The muscular pulmonary arteries (100 to $1000 \mu$ in diameter) showed a gross increase in medial thickness (Fig. 2b). Arteries of about $200 \mu$ in diameter, for example, had a medial thickness equivalent to 25 per cent of the external diameter of the vessel and a medial cross-sectional area of about 26,000 sq. micra. Normal muscular pulmonary arteries in the adult have a medial thickness of 5 per cent or less and a medial cross sectional area of 1900 sq. micra, with the exception of arteries in the lingular area (Heath and Best, 1958). There was a considerable development of longitudinally-orientated muscle in the outer part of the media (Fig. 2b). Some muscular arteries were the site of minimal cellular intimal fibrosis and others the site of intimal fibro-elastosis with reduplication of the internal elastic lamina. Generalized arterial dilatation and complex, localized "dilatation lesions" were absent.

Pulmonary arterial vessels below $100 \mu$ in diameter showed the distinct muscular media and limiting internal elastic laminæ so characteristic of pulmonary arterial hypertension (Fig. 2c). The wall of the normal arterial vessel of this size consists solely of an elastic lamina and is indistinguishable from a pulmonary venule. Even tiny arterioles of $30 \mu$ in diameter had thick muscular walls. Small pulmonary veins had abnormally thick walls consisting of smooth muscle bounded by internal and external elastic laminæ so that they resembled arteries (Fig. 2d).

There was severe pulmonary hæmosiderosis. Numerous intra-alveolar hæmosiderin-laden macrophages were found throughout the lung, either scattered diffusely or grouped to form nodules measuring up to $400 \mu$ in diameter (Fig. 3c). Many of these nodules were in a subpleural position.

The elastic laminæ of some pulmonary arteries, arterioles, and veins were incrusted with iron, both of a ferric and ferrous nature, as demonstrated by positive staining by Perls' reagents and by Turnbull's method respectively (Fig. 3a and b). Staining by von Kossa's method demonstrated the presence of a small amount of calcium and phosphate. The elastica of the alveolar walls and the musculo-elastic bundles of alveolar ducts were similarly affected. This incrustation with iron was patchy in many vessels.

\section{Discussion}

We consider it likely that the organic mitral regurgitation was congenital in origin as there was no clinical history of rheumatic fever and no histological evidence of this disease on careful examination of the myocardium and valves. Rheumatism severe enough to have produced this degree of structural change in the mitral valve by the age of $6 \frac{1}{2}$ years would surely leave histological evidence of its presence. Even apparently quiescent cases of mitral stenosis in adult life are frequently characterized by Aschoff nodes and interstitial hæmatoxyphil substance in the endocardium of the left auricular appendage. We regard the endocardial fibro-elastosis present as congenital in origin and do not consider it to be evidence of a previous rheumatic or fœtal inflammation.

Structural Changes in the Lung Biopsy. The severe pulmonary arterial hypertension in this case acted upon the small pulmonary arterial vessels to produce the customary medial hypertrophy and intimal fibrosis in the small muscular pulmonary arteries (Fig. 2b) and the development of a muscular media in the pulmonary arterioles (Fig. 2c). These structural changes are those of only moderately severe hypertensive pulmonary vascular disease, a stage beyond which patients with mitral stenosis do not appear to proceed. The pulmonary venous hypertension, which must have existed in this boy becáuse of the mitral lesion, had given rise to severe pulmonary hæmosiderosis (Fig. 3c), probably by rupture of pulmonary venules and capillaries with the liberation of blood into the alveolar spaces. The striking feature of this case, however, is the incrustation of iron on the elastic laminæ of pulmonary arteries and veins (Fig. 3a and b), which appears to be an expression of the large amounts of free iron present in the lung. Since the later stages of hypertensive pulmonary vascular disease without pulmonary venous hypertension are also characterized by pulmonary hæmosiderosis (Heath and Edwards, 1958) resulting from rupture of distended vein-like branches of hypertrophied muscular arteries, it would be expected that iron incrustation of elastic laminæ would occur in these circumstances. Indeed, this unusual histological appearance, first given prominence by Lendrum (1950), can occur whenever thin-walled vessels in the lung lead to bleeding into alveolar spaces as in bronchiectasis (Cameron, 1956). However, the finding of iron incrustation 
of elastic laminæ and pulmonary hæmosiderosis in the biopsy of lung in association with a comparatively early stage of hypertensive pulmonary vascular disease in this case was of practical significance in indicating that, in addition to the widely patent ductus arteriosus already suspected, there was a cardiac lesion associated with pulmonary venous hypertension. At autopsy this additional cardiac disease proved to be organic mitral regurgitation. It is of interest to recall a reported case of widely patent ductus arteriosus with unilateral pulmonary hæmosiderosis (Emslie-Smith et al., 1955). In that instance the hæmosiderosis in the right lung followed pulmonary venous hypertension resulting from obstruction of the venous return by a membranous occlusion of the right pulmonary veins. Other diseases with pulmonary arterial hypertension where iron incrustation of elastic laminæ might be found before the development of arterial "dilatation lesions" owing to associated pulmonary venous hypertension are chronic rheumatic or congenital mitral stenosis, myxoma of the left atrium, mediastinal masses occluding pulmonary veins, and diffuse myocardial fibrosis. As in the cases reported by Cameron (1956), the mineral incrusted on the elastic laminæ contained ferric and ferrous iron with much smaller quantities of calcium and phosphate.

The pulmonary venous hypertension in this case led to hypertrophy of the media of the pulmonary veins so that these vessels resembled muscular pulmonary arteries (Fig. 2d). This response of the muscle in the wall of pulmonary veins to hypertension has been recognized in several congenital and acquired diseases of the heart (Edwards and Burchell, 1951; Heath and Edwards, 1959).

The configuration of the elastic tissue in the elastic pulmonary arteries, resembling that of the adult aorta or the fœtal pulmonary trunk (Fig. 2a) provided additional confirmation that the severe pulmonary arterial hypertension in the patient had been present from birth. This has been demonstrated previously in a large group of cases of congenital heart disease (Heath et al., 1959).

If it is accepted that severe pulmonary arterial hypertension was present from birth and was due to the congenital mitral valvular deformity, then it would follow that in this case the patent ductus arteriosus had served from birth as an essential shunt. The peripheral circulatory failure ensuing from its closure is, therefore, understandable. Though the present combination of cardiac abnormalities is unusual, it serves to illustrate the important fact that, in cases presenting with patency of the ductus, coincident pulmonary hypertension may be present and due to an associated underlying cardiac abnormality that may contra-indicate operative closure of the ductus. The present case demonstrates the importance of pre-operative lung biopsy, for in this boy the histological changes were characteristic of pulmonary venous hypertension and clearly showed that the dominant pulmonary arterial hypertension was associated with another disease in addition to the patent ductus.

\section{Summary}

A boy aged $6 \frac{1}{2}$ years presented with clinical signs suggestive of a patent ductus arteriosus with pulmonary hypertension. A lung biopsy showed pulmonary hæmosiderosis with iron incrustation of the laminæ of the small pulmonary blood vessels, changes associated with severe pulmonary venous hypertension. At autopsy mitral valve disease believed to be congenital was found. The importance of searching for additional cardiac disease in patients with patent ductus and pulmonary hypertension is stressed and the role of lung biopsy in this connection is demonstrated.

We wish to thank Mr. A. L. d'Abreu and Dr. C. Parsons for permission to report this case and for access to their records, Dr. A. H. Cameron for allowing us to quote his report on the biopsy, and Mr. G. Billington, H. M. Coroner for the City of Birmingham, for giving us leave to publish the autopsy findings.

Cameron, A. H. (1956). Thorax, 11, 105.

\section{References}

Edwards, J. E., and Burchell, H. B. (1951). Arch. intern. Med., 87, 372.

Emslie-Smith, D., Hill, I. G. W., and Lowe, K. G. (1955). Brit. Heart J., 17, 79.

Heath, D., and Best, P. V. (1958). J. Path. Bact., 76, 165.

-, and Edwards, J. E. (1958). Circulation, 18, 533.

- - (1959). Brit. J. Dis. Chest., 53, 8.

-, Wood, E. H., Du Shane, J. W., and Edwards, J. E. (1959). J. Path. Bact., 77, 443.

Lendrum, A. C. (1950). J. Path. Bact., 62, 555. 